\title{
Effects of Aquatic Therapy on Vagal Tone and Social Behaviors in Individuals with Autism Spectrum Disorder
}

\author{
Brittany Bell, PhD
}

Department of Applied Social Psychology, Claremont Graduate University, 150 E 10th St, Claremont, CA 91711, United States

\author{
Article Details \\ Article Type: Research Article \\ Received date: $05^{\text {th }}$ February, 2021 \\ Accepted date: $15^{\text {th }}$ March, 2021 \\ Published date: $17^{\text {th }}$ March, 2021
}

*Corresponding Author: Brittany Bell, PhD, Department of Applied Social Psychology, Claremont Graduate University, 150 E 10th St, Claremont, CA 91711, United States. E-mail: brittany.bell@,cgu.edu

Citation: Bell, B. (2021). Effects of Aquatic Therapy on Vagal Tone and Social Behaviors in Individuals with Autism Spectrum Disorder. J Rehab Pract Res 2(1):115. https://doi.org/10.33790/jrpr1100115

Copyright: (C2021, This is an open-access article distributed under the terms of the Creative Commons Attribution License $\underline{4.0}$, which permits unrestricted use, distribution, and reproduction in any medium, provided the original author and source are credited.

\begin{abstract}
s
Aquatic therapy has shown behavioral benefits for participants with autism spectrum disorder (ASD), including social and swimming skills. The mechanism through which aquatic therapy has these effects has not been demonstrated. The present study evaluated the effect of aquatic therapy on vagal tone and behavior in participants with and without ASD $(\mathrm{N}=64)$. Measures consisted of social, swimming, emotional and cognitive tasks. Following the aquatic intervention participants with ASD demonstrated an increase in vagal tone while typically developing participants displayed a decrease. The change in vagal tone was positively correlated with social skills in participants with ASD. This study identifies vagal tone a mechanism through which aquatic therapy increases social, emotional and cognitive abilities in those with ASD.
\end{abstract}

Keywords: ASD, swimming, social skills, vagal tone

\section{Introduction}

Individuals with ASD typically display communication and social behavior deficits (DSM-V). While social skills are a primary focus of treatment for children with ASD, additional needs are not addressed in standard therapy. Children with ASD display a high attraction to water $[1,2]$. This attraction, along with eloping frequently, difficulty generalizing skills and lack of specialized services place children with ASD at risk for drowning [3-5]. Children with ASD are 160 times more likely to drown than a typically developing child [3]. Although these rates are alarmingly high, many parents are unaware of this risk [5].

Aquatic therapy has addressed the risk of drowning for children with ASD and their social skills deficits. Aquatic interventions have proven successful in teaching swimming and water safety skills to individuals across the spectrum $[1,6]$. In addition to improving swim skills, the participants also displayed increases in social skills such as eye contact and communication, along with decreases in antisocial behavior such as stimming $[1,6]$. However, it is unclear why aquatic interventions produced improvements in social skills.

The mechanism through which aquatic therapy has these effects has not been demonstrated. Polyvagal theory emphasizes that the vagus nerve regulates social behaviors, which are compromised in individuals with ASD [7]. The vagus nerve is also considered to link the autonomic nervous system to verbal and facial expressions as well as social behavior [7]. The act of swimming includes several methods effective in increasing vagal tone activity including; exposure to cold temperatures, deep and slow breathing and exercise
[8-10]. While submerged in water, the body produces a hormonal balance that imitates the balance found during meditation or deep relaxation [11]. This meditative state while swimming may increase vagas nerve activation. Lastly, socialization a component of aquatic programs, has been effective in activating thevagus nerve [12].

The present study sought to explain how aquatic interventions produce improvements in socials skills of children with ASD. The experiment assessed vagal tone activity before and after the aquatic intervention to determine the association between vagal tone and social skills in children with ASD. The author hypothesized that during aquatic interventions, children with ASD experienced an increase in vagal tone activity and developed appropriate social skills.

\section{Method}

\section{Participants}

Sixty-four subjects participated in this study. Half of the participants were typically developing, and the other half were individuals diagnosed with ASD. The participants were recruited through Facebook advertisements. The participants were assessed with Childhood Autism Syndrome Test [13].

\section{Materials}

A Rhythm+ heart rate monitorwas utilized during this study to measure vagal tone. The vagal tone monitor is a small armband that collects information about the participants' heart rate variability. Participants wore the monitor during cognitive and socioemotional tasks before and after the aquatic session.

\section{Setting}

This study took place in two locations. The first day of the study took place in a quiet lab space at Claremont Graduate University. Here the study was explained verbally and through written materials to the participants and their guardians. Next, the parents completed several surveys about their backgrounds and their child's background and swim experience (see appendix A and B) and completed the Childhood Autism Spectrum Test (CAST) assessment. The study's second day took place at an aquatic center. Participants engaged in cognitive and socioemotional tasks at a table on the deck of the aquatic center.

\section{Procedure}

\section{Pre-Intervention}

Participants engaged in several cognitive and socio-emotional tasks outside of the water at the aquatic center before beginning the aquatic intervention. 


\section{Resting Phase}

Resting baseline phase was conducted prior to the aquatic session. During this phase, the participant sat still and quietly for two minutes while wearing the vagal tone monitor.

\section{Counting Task}

Next, the participant was asked to count from one to five verbally and on their fingers. The researcher counted along with them.

\section{Reading The Mind in The Eyes Assessment}

The participant was then asked to complete the Reading the Mind to view pictures of people's eyes. Each picture hadfour words around it. The researcher then asked the participant to look carefully at the picture and then choose the word that best describes what the person in the picture was thinking or feeling.

\section{Play Probe}

Finally, the participant engaged in a five-minute play probe. During the play probe, the researcher announced that it is time to play and presented a toy bin to the participant. The participant was encouraged to select a toy or toys out of the bin.

\section{Aquatic Intervention}

The aquatic intervention took approximately 20 minutes and was tailored to the participant's aquatic skill level. The participant could have practiced swimming skills such as blowing bubbles, submersion and was implemented across all skill levels. For those who are beginners, submersion included first learning how to blow bubbles. For more advanced swimmers, submersion included tasks such as front crawl lap swimming and diving underwater to retrieve diving toys.

\section{Post Intervention}

Following the aquatic intervention, the participants repeated the cognitive and socio-emotional tasks from the pretreatment phase.

\section{Dependent Measures}

Social behaviors included eye contact, verbalizations, and appropriate play. The operational definition of eye contact is mutual gaze and a signal of interest and intention toward the perceiver [14]. Verbalizations are classified as any form of verbal communication or attempted communication [15]. Lastly, the operational definition of appropriate play included behaviors such as cooperative play with others, appropriate use of toys as well as initiating and accepting play bids $[16,17]$.

\section{Measurement}

This study used a partial interval scoring procedure to determine the occurrence of eye contact, verbalizations, and appropriate play during the behaviors occurred or did not occur during each 10-second interval for every recorded session. The number of intervals that the behaviors occur was divided by the total number of possible intervals (i.e., 30) to yield the percentage of occurrence for the 5-min session.

Cardiac and vagal tone activity were collected using a Rhythm+ heart rate monitor and recorded with Immersion Neuroscience software [18]. To measure vagal tone activity, participants were fitted with the Rhythm+ armband on their forearm. Before the placement of the monitor, participants dried off completely.

Following data collection, the data was inspected using Immersion Neuroscience platform. Cardiac waveforms were visually inspected for brief periods of signal loss, and data drop-offs shorter than $1 \mathrm{~s}$ in length was replaced with the averages from adjacent parts of the waveform. Additionally, waveform noise due to experimenterobserver movement was smoothed using mean-value replacement from adjacent parts of the waveform. Next, a $10-\mathrm{Hz}$ low pass filter was applied to the waveform to remove high-frequency noise [19]. in The Eyes assessment. During this task, the participant was asked kicking and arm stroke technique. The intervention also focused on 10 -second intervals within a 5 -min session. Coders indicated whether

After transformations, the average vagal tone level was extracted from the pre-intervention session and from the post-intervention session [20]. These values were used to calculate the changes in vagal tone activity from pre to post intervention.

\section{Reliability}

A second observer was trained by the first author, and coded $33 \%$ of all sessions in each phase by measuring eye contact, verbalizations and appropriate play behaviors using the same scoring procedure. Phases of this study included the preintervention play probe, the aquatic session, and post-intervention play probe. Inter-observer agreement (IOA) was calculated by dividing the total number of agreements by the total number of disagreements plus agreements, and then multiplying this number

\section{Case Study}

Patrick is a 15-year-old Caucasian and Hispanic American male with ASD. He was previously diagnosed by outside therapists and schools. According to the CAST (23) Patrick had severe autism. In terms of communication, Patrick did not produce spontaneous words. According to his mother and therapists, Patrick has been non-verbal his entire life.

Prior to intervention Patrick did not speak. He engaged in vocal stereotypy but did not engage in communication. Patrick made eye contact less then $1 \%$ across opportunities. He did not engage in imaginative or cooperative play.

During the aquatic intervention, Patrick said his first word and phrase. He stated, "take the squid!" while working with the instructor. During the aquatic intervention Patrick also displayed an increase in eye contact, imaginative play and cooperative play.

Following the aquatic intervention, Patrick continued to make verbalizations totaling in 7 words and 20 phrases. In addition, he displayed a significant increase in eye contact, imaginative play and cooperative play. His mother was overjoyed by the outcome of his participation in the study.

\section{Results}

Data was collected and analyzed for 64 participants, 32 participants with autism spectrum disorder $(73 \%$ male, mean age of $=9.74$, $\mathrm{SD}=5.44)$ and 32 typically developing participants $(76 \%$ male, mean age of $=9.22, \mathrm{SD}=6.12$ ) each of whom participated in the aquatic intervention. Changes in vagal tone were analyzed using independent samplest tests, contrasting measures prior to and following an aquatic intervention. Paired-samples $t$ tests were used to test differences in pre and post treatment social, emotional, cognitive and swim skills measures. Bivariate correlations were used to assess the correlation between vagal tone and social, emotional, cognitive and swim skills.

\section{Vagal Tone}

Participants with ASD displayed a significant increase in vagal tone following the swimming intervention (preM=8.08, $\mathrm{SD}=6.56$; postM=9.57, $\mathrm{SD}=1.07 ; \mathrm{t}=6.63$ (31), $\mathrm{p}=.000$ ).

Conversely, typically developing participants displayed a significant decrease in vagal tone following the swimming intervention (preM=7.00, $\mathrm{SD}=4.52$, post $\mathrm{M}=6.43, \mathrm{SD}=4.49 ; \mathrm{t}=6.78$ (31), $\mathrm{p}=.000)$.

\section{Swim Skills}

Significant increases in swimming and water safety skills were present in both participant groups Participants with ASD displayed a significant increase in swim and water safety skills following the swimming intervention ( $\mathrm{preM}=3.58, \mathrm{SD}=1.81$; postM=4.11, $\mathrm{SD}=3.59 ; \mathrm{t}=11.55 \mathrm{p}=.000$ ). Typically developing participants also displayed a significant increase in swim and water safety skills following the swimming intervention (preM= 5.19, $\mathrm{SD}=2.66$; postM=5.90, $\mathrm{SD}=2.02 ; \mathrm{t}=11.55 \mathrm{p}=.000)$. 


\section{ASD}

12

10

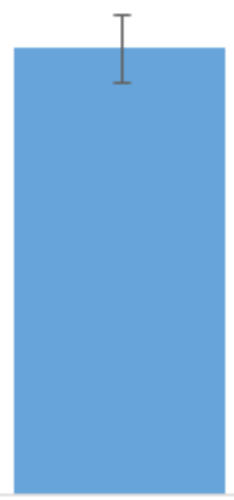

Pre

Post

\section{Vagal Tone}

Figure 1. ASD Vagal Tone.

\section{Social Skills}

Significant increases in social skills measures were seen in both participants with ASD and typically developing participants during free play probes.

Verbal Communication

This first social skills measure to be discussed is verbal communication, a common deficit in individuals with ASD.
Both groups displayed significant increases in language following the swimming intervention. Participants with ASD displayed a significant increase in the number of words stated following the aquatic intervention (preM=3.05, $\mathrm{SD}=3.11$; postM=8.56, $\mathrm{SD}=6.86$; $\mathrm{t}=5.73(31), \mathrm{p}=.000)$.

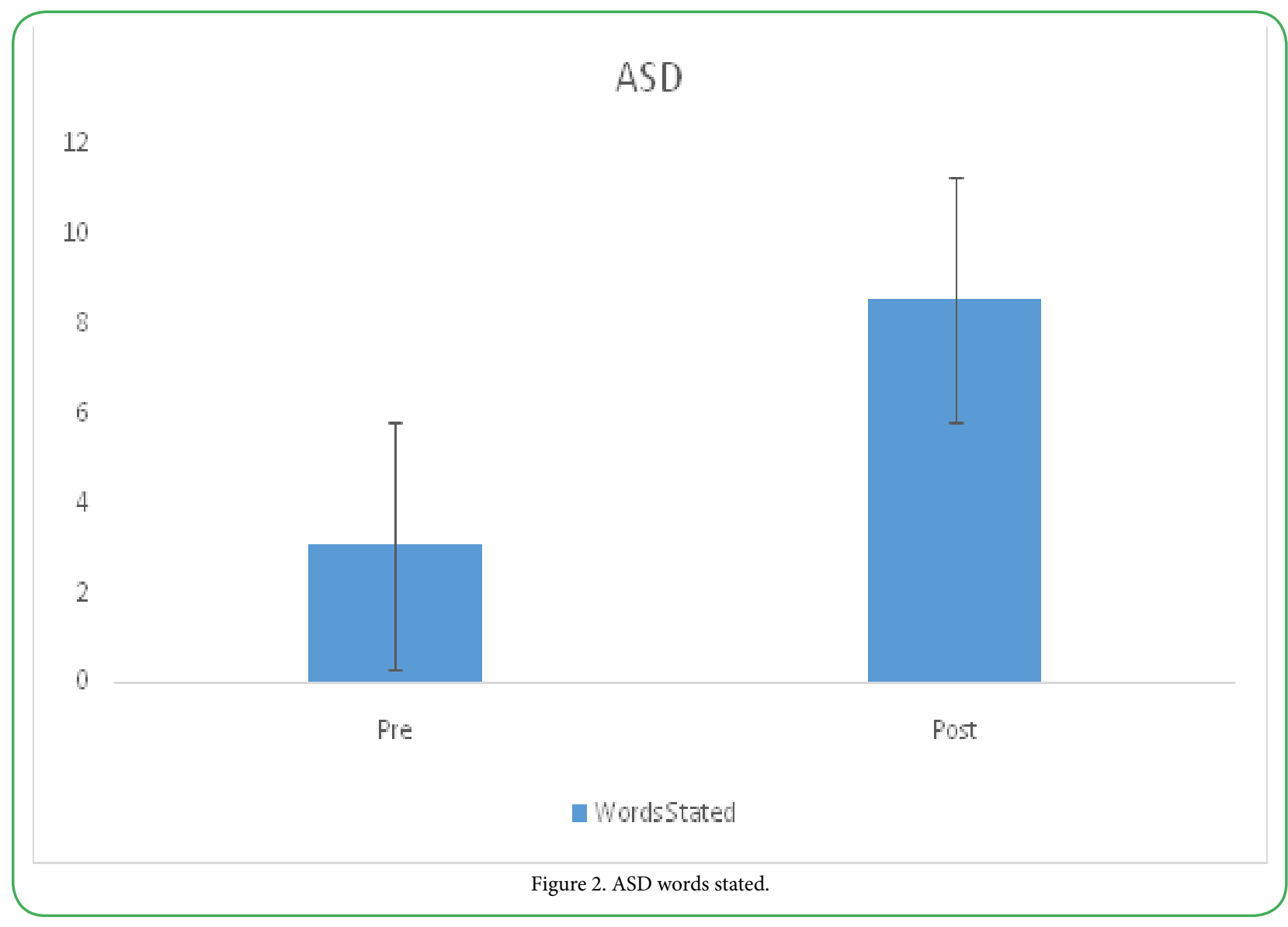


Children with ASD also had a significant increase in the number of phrases stated following the aquatic intervention (preM=6.29, $\mathrm{SD}=$ 9.10; postM=13.47, $\mathrm{SD}=9.84 ; \mathrm{t}=4.03$ (31), $\mathrm{p}=.000$ ).

Similarly, significant increases in words and phrases said were also present in the typically developing group. The control group demonstrated a significant increase in the number of words stated following the aquatic intervention ( $\mathrm{preM}=4.08, \mathrm{SD}=2.68$; post $\mathrm{M}=7.85, \mathrm{SD}=5.15 ; \mathrm{t}=6.91$ (31), $\mathrm{p}=.000$ ). Typically developing participants also demonstrated a significant increase in the number of words stated following the aquatic intervention (preM=10.18, $\mathrm{SD}=$ 8.16; postM=18.43, $\mathrm{SD}=10.31 ; \mathrm{t}=5.77$ (31), $\mathrm{p}=.000)$.

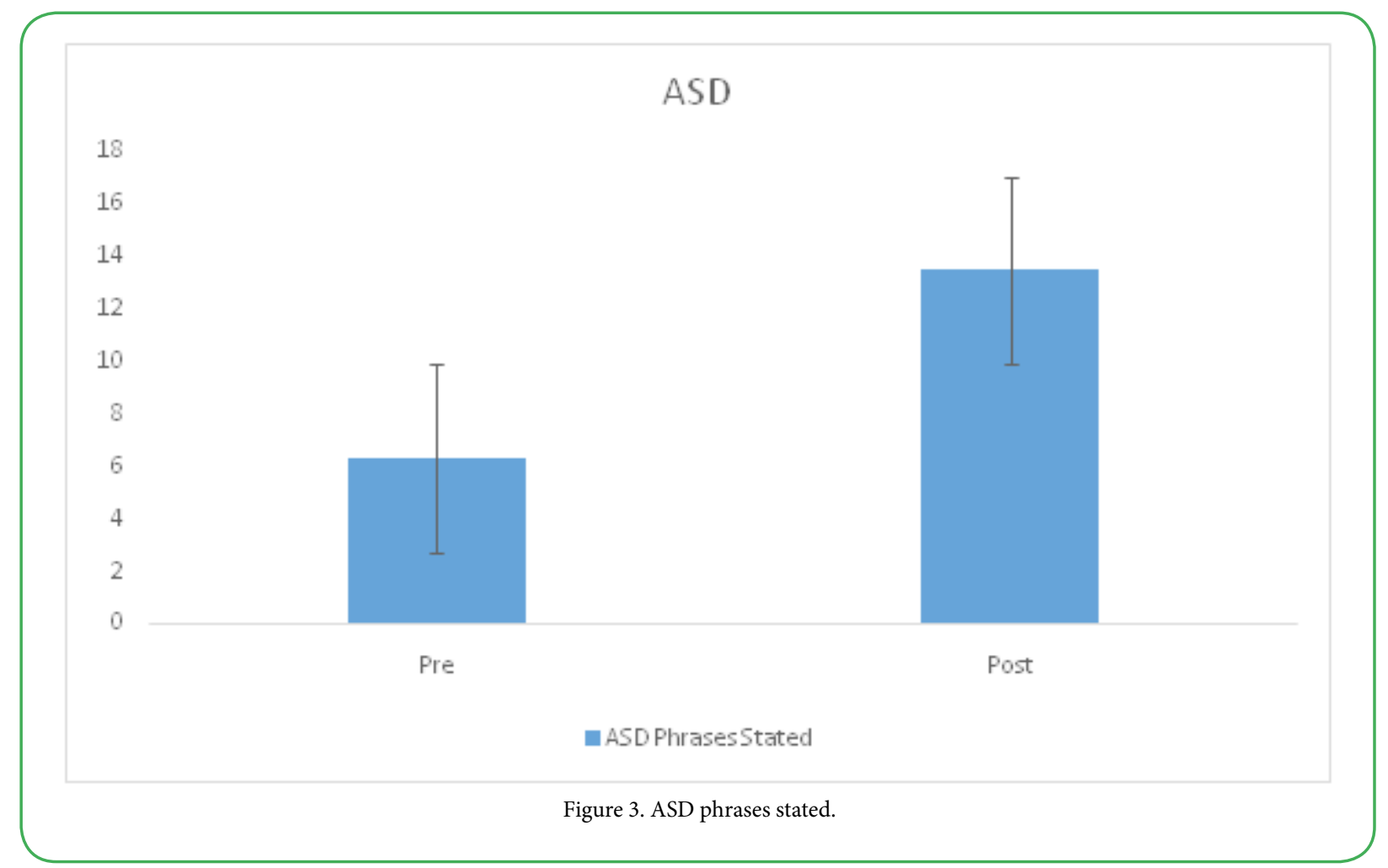

\section{Eye Contact}

Engaging in eye contact a common deficit in individuals with ASD. Following intervention, participants with ASD displayed a significant increase in the amount eye contact made. Participants with ASD demonstrated a significant increase in the number of times eye contact was made following intervention (preM= 1.20, $\mathrm{SD}=1.95 ;$ postM=6.35, $\mathrm{SD}=4.87 ; \mathrm{t}=2.60$ (31), $\mathrm{p}=.000$ ).
A positive correlation between eye contact and vagal tonewas present in the participants with ASD $(\mathrm{r}=.55, \mathrm{p}=.002)$.

Typically developing children also demonstrated a significant increase in eye contact following the swimming intervention. The control group demonstrated a significant increase in the amount of eye contact made following treatment ( $\mathrm{preM}=4.08, \mathrm{SD}=2.68$; post $\mathrm{M}=6.35, \mathrm{SD}=9.14 ; \mathrm{t}=4.85(31), \mathrm{p}=.000)$.

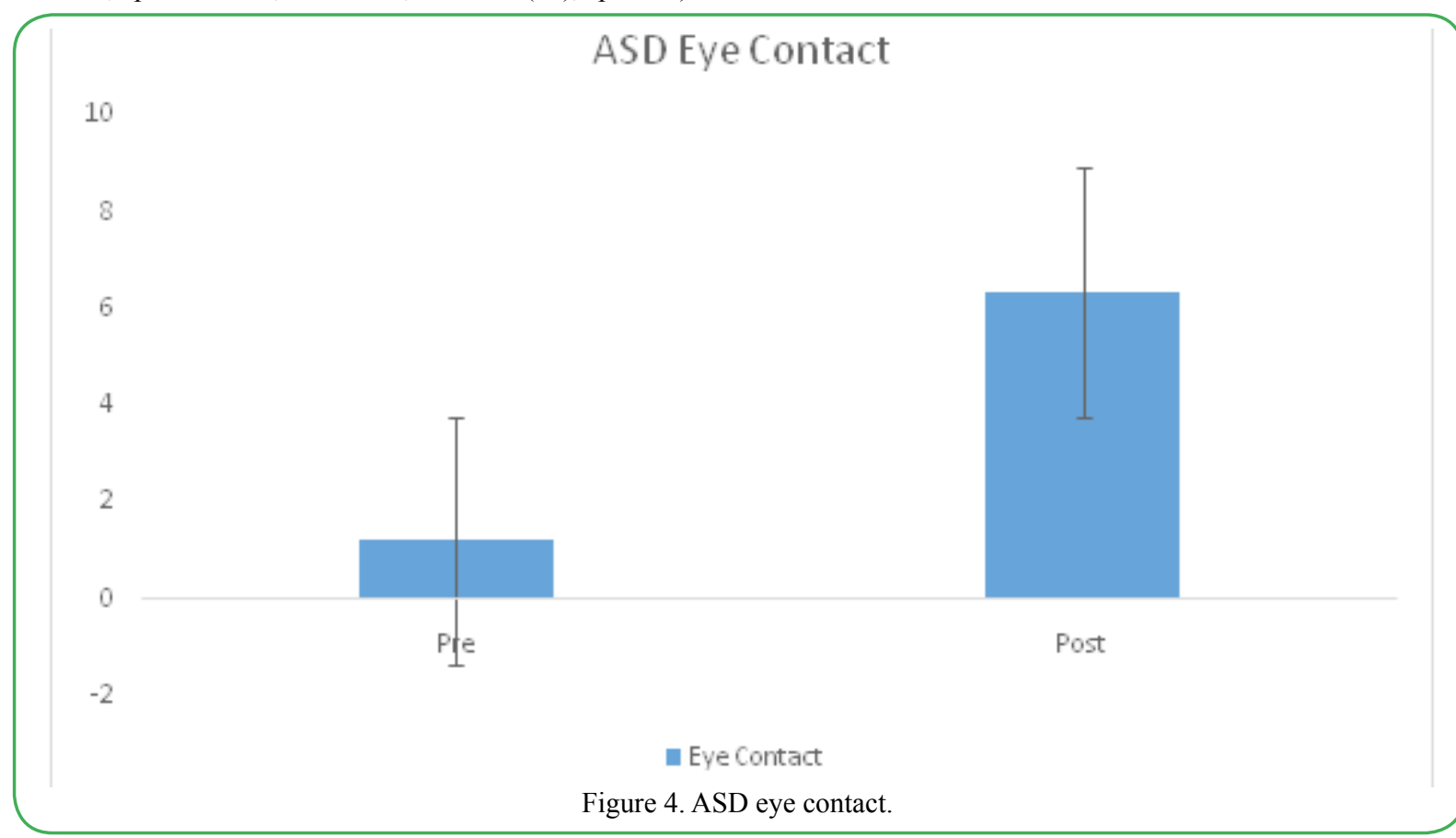




\section{Laugh}

The frequency of the participants' laughing was assessed prior to and following the aquatic intervention. The participants with ASD demonstrated a significant increase in the number of times they laughed following treatment (preM=4.08, $\mathrm{SD}=2.68$; postM=9.14, $\mathrm{SD}=6 ; \mathrm{t}=4.85$ (31), $\mathrm{p}=.000)$. A positive correlation between vagal tone and laughing was found in participants with ASD ( $r=.47$, $\mathrm{p}=.005)$.

Typically developing children also displayed a significant increase in laughing following the aquatic intervention treatment (preM= 2.14, $\mathrm{SD}=2.69$; postM=4.57, $\mathrm{SD}=2.20 ; \mathrm{t}=9.50$ (31), $\mathrm{p}=.000)$.

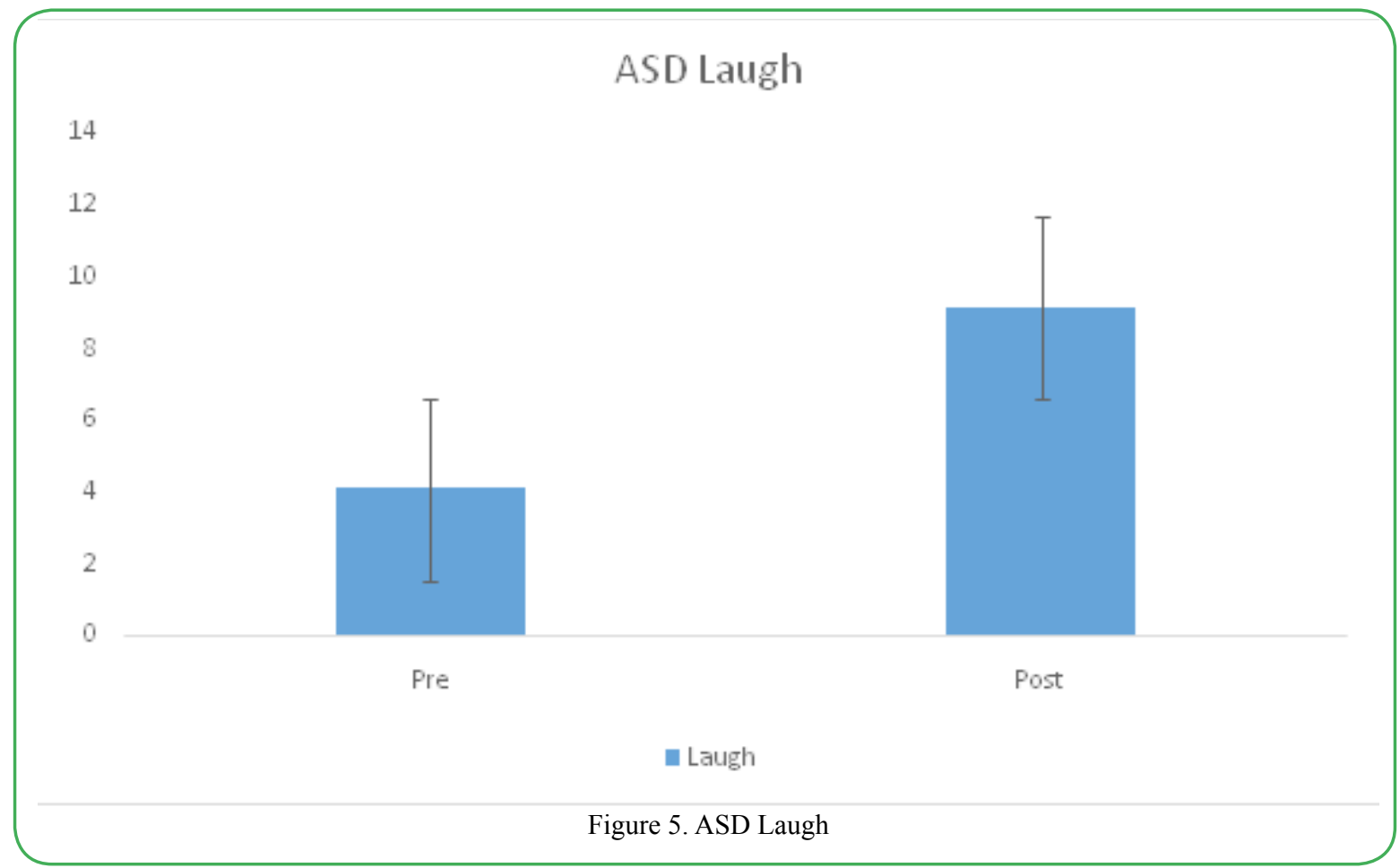

\section{Imaginative Play}

Imaginative play is an activity that children with ASD do not typically engage in. The frequency of imaginative play was assessed prior to and following the aquatic intervention. Participants with ASD demonstrated a significant increase in the number of times they engaged inimaginative play following the aquatic intervention
$($ preM= .26, $\mathrm{SD}=.79 ;$ postM=1.56, $\mathrm{SD}=1.48 ; \mathrm{t}=6.40(31), \mathrm{p}=.000)$.

Typically developing participants also displayed a significant increase in the number of times they engaged in imaginative play following treatment (preM=1.66, $\mathrm{SD}=2.03$; postM=3.09, $\mathrm{SD}=1.79$; $\mathrm{t}=7.94(31), \mathrm{p}=.000)$.

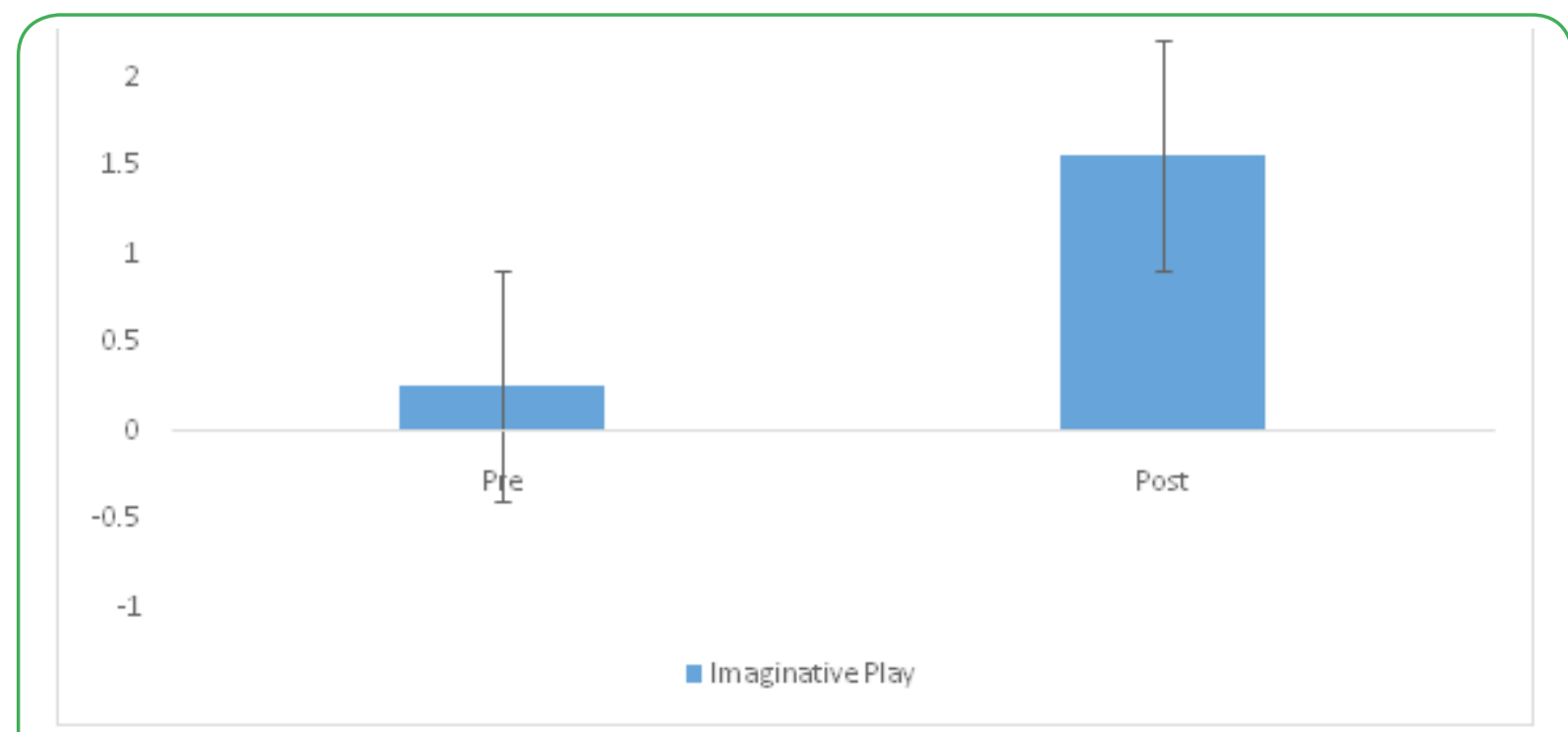

Figure 6. ASD imaginative play.

\section{Cooperative Play}

Cooperative play is characterized by play involving working together to achieve a common goal. Given their social skills deficit, individuals with ASD have difficulty engaging in cooperative play. Participants with ASD displayed a significant increase in the numbe of times they engaged in cooperative play following treatment
$($ preM= $82, \mathrm{SD}=.75 ;$ postM=2.68, $\mathrm{SD}=1.71 ; \mathrm{t}=6.33(31), \mathrm{p}=.000)$.

Typically developing participants also demonstrated a significant increase in the number of times they engaged in cooperative play following treatment (preM=1.76, $\mathrm{SD}=1.37$; postM=3.09, $\mathrm{SD}=1.79$; $\mathrm{t}=5.87(31), \mathrm{p}=.000$ ). 


\section{ASD Cooperative Play}

4

3.5

3

2.5

2

1.5

1

0.5

0

$-0.5$

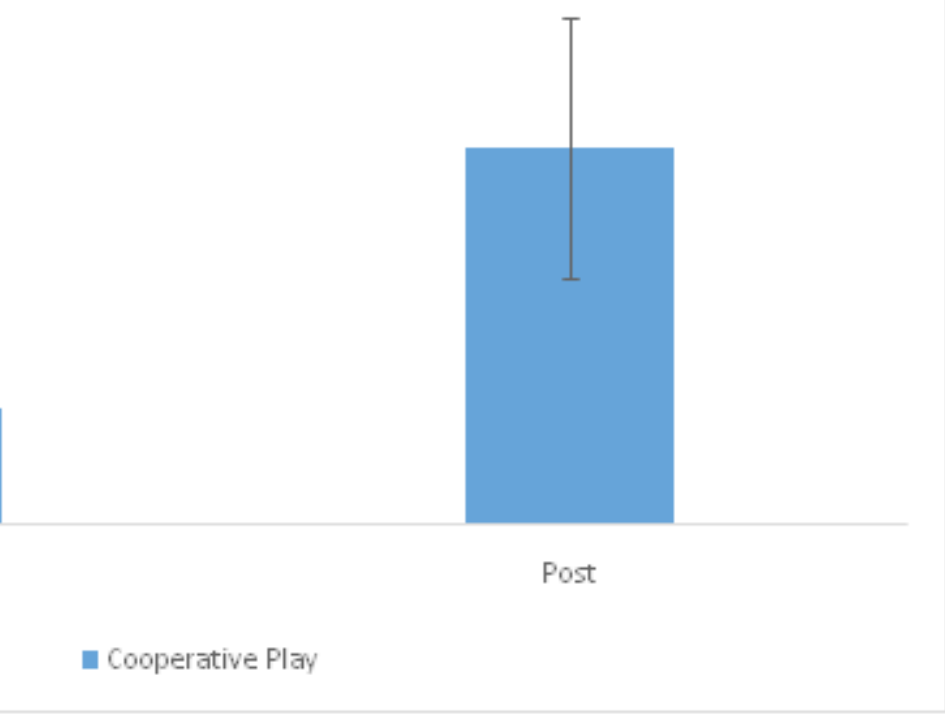

Figure 7. ASD cooperative play.

\section{Initiate Bids for Joint Play}

Children with ASD do not frequently initiate social interactions with others. However, both groups in the study displayed a significant increase in initiating bids for play. Prior to intervention, participants with ASD initiated an average of $(\mathrm{M}=.91, \mathrm{SD}=1.46)$ bids, following the aquatic intervention the same participants initiated an average of $(\mathrm{M}=1.55, \mathrm{SD}=1.24)$ bids, $\mathrm{t}=3.61$ (31), $\mathrm{p}=.001$.

Typically developing children displayed a smaller but also significant increase in initiation of play bids. Prior to intervention the control group initiated an average of $(\mathrm{M}=1.62, \mathrm{SD}=1.50)$ bids, following the aquatic intervention the same participants initiated an average of $(\mathrm{M}=1.67, \mathrm{SD}=1.43)$ bids, $\mathrm{t}=4.95$ (31), $\mathrm{p}=.000$.

\section{Smile}

Participants with ASD and typically developing participants both displayed a significant increase in the number of times they smiled following the aquatic intervention. Prior to intervention participants with ASD displayed an average of $(\mathrm{M}=2.5, \mathrm{SD}=2.93)$ smiles, following the aquatic intervention the participants with ASD smiled an average of $(\mathrm{M}=6.68, \mathrm{SD}=5.25)$ times, $\mathrm{t}=4.97(31), \mathrm{p}=.000$.

Typically developing children displayed a similar significant increase in smiling. Prior to intervention the control group smiled an average of $(\mathrm{M}=3.95, \mathrm{SD}=3.11)$ bids, following the aquatic intervention the same participants initiated an average of $(\mathrm{M}=8.00$, $\mathrm{SD}=3.77$ ) bids, $\mathrm{t}=5.82(31), \mathrm{p}=.000$.

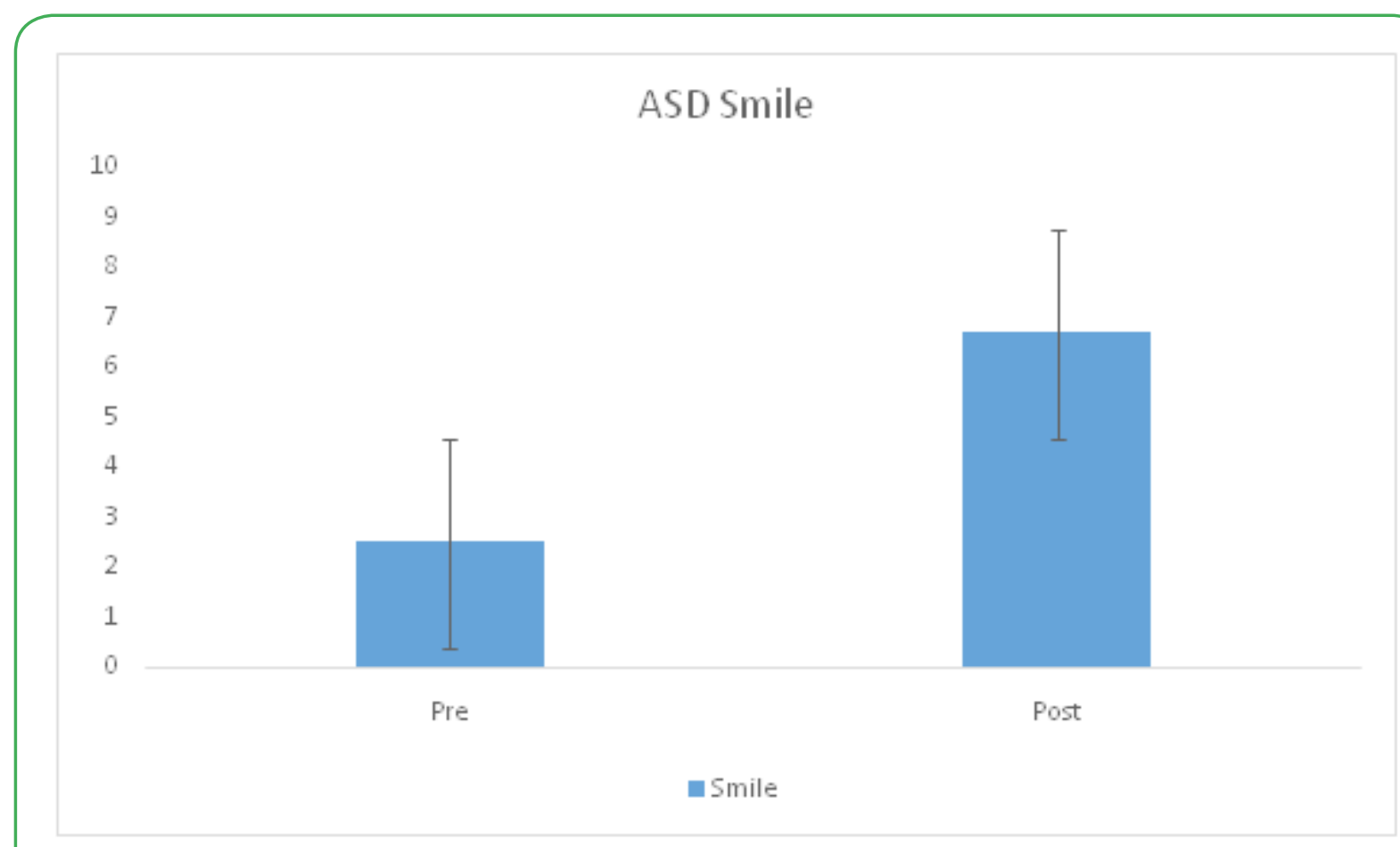

Figure 8. ASD smile. 


\section{Socioemotional Skills}

\section{Reading the Mind in the Eyes}

This tool is used to describe the socioemotional states of individuals with and without ASD. Previous studies have shown that those with ASD have impairments in theory of mind [22]. In the current study, participants were given the Reading the Mind in the Eyes assessment prior to and following the aquatic intervention. Both participant groups displayed a significant increase in the number of correct responses to the Reading the Mind in the Eyes assessment following the aquatic intervention. Prior to intervention, participants with ASD answered an average of $(\mathrm{M}=3.47, \mathrm{SD}=3.36)$ correct trials, following the aquatic intervention the participants with ASD provided an average of $(\mathrm{M}=5.67, \mathrm{SD}=4.47)$ correct trials, $\mathrm{t}=6.02(31), \mathrm{p}=.000$.

Typically developing participants displayed a similar significant increase in correct responses. Prior, to intervention the control group answered an average of $(\mathrm{M}=6.48, \mathrm{SD}=3.36)$ correct trials, following the aquatic intervention the control group provided an average of $(\mathrm{M}=8.71, \mathrm{SD}=3.13)$ correct trials, $\mathrm{t}=8.80$ (31), $\mathrm{p}=.000$.

\section{Cognitive Abilities}

Participant's ability to count outloud and on their fingers was assessed prior to and following the aquatic intervention. Participants were awarded one point for each of the following counting out-loud, counting on their fingers, and counting fully to the number of five earing a total of 3 points. Significant increases in counting abilities were seen in both participant groups. Prior to treatment, participants with ASD scored an average of $(\mathrm{M}=2.59, \mathrm{SD}=.74)$ on the counting task and an average score of $(\mathrm{M}=2.65, \mathrm{SD}=.81)$ post treatment $\mathrm{t}=19.06$ (31), $\mathrm{p}=.000$. Typically developing participants scored an average of $(\mathrm{M}=2.67, \mathrm{SD}=.80)$ prior to treatment, following treatment the control group scored an average of $(\mathrm{M}=2.86, \mathrm{SD}=.65), \mathrm{t}=15.36$ (31), $\mathrm{p}=.000$.

\section{Correlations}

Several positive correlations between vagal tone and social behaviors were observed. A positive correlation between eye contact and vagal tone was present in the participants with ASD $(r=.55$, $\mathrm{p}=.002$ ). A positive correlation between vagal tone and Laughing was also noted in participants with ASD $(r=.47, p=.005)$.

\section{Discussion}

The results of the present study indicated that the aquatic intervention successfully increased vagal tone and promoted social skills and swimming skills in participants with ASD. In addition, the aquatic intervention also yielded significant increases in social and swimming skills in typically developing participants.

The aquatic intervention may have led to rapid acquisition of social skills in children with autism spectrum disorder for a number of reasons. First, the aquatic intervention lead to an increase in vagal tone. It is known that individuals with ASD display decreased basal vagal tone levels [22-25] and that vagal tone is associated with a variety of social behaviors [7, 26]. Increasing vagal tone levels may be associated with the increase in social skills. The present study found positive correlations between eye contact and vagal tone levels $(\mathrm{r}=.55, \mathrm{p}=.002)$ as well as laughing and vagal tone levels $(\mathrm{r}=.47, \mathrm{p}=.005)$

Second, the aquatic intervention provides a reduced stimulus setting. Individuals with ASD often present or report symptoms pertaining to over stimulation in their environments. The aquatic intervention provided a setting where the participants could easily reduce auditory stimuli by submerging underwater. In addition to allowing participants relief from auditory stimuli, aquatic environments provide hydrostatic pressure. Hydrostatic pressure provides equal and comfortable resistance to all submerged portions of the body $[27,28]$. This process has an alleviating and calming effect on individuals with ASD [29]. The reduced-stimuli and relaxing setting may have provided an optimal setting for an individual with ASD to interact with others.
Lastly, aquatic activities tend to be a preferred activity among individuals with ASD. 98\% of the participant's parents reported that their child was highly attracted to water. Previous research also found that children with ASD are deeply drawn to water $[1,2]$. Participating in a preferred activity motivates individuals with ASD to engage in social behaviors and verbalizations more frequently than in a non-preferred activity.

Aquatic intervention addresses several needs of individuals with ASD including deficits in social skills as well as water safety and swimming skills. Since the intervention provides treatment in two crucial areas of development in individuals with ASD, replication of the treatment is important. A limitation of this program is access to an aquatic facility. However, facilities can be found in local community centers, high schools and physical therapy or occupational therapy centers. Since autism is a spectrum disorder, it is recommended that during replication the treatments are tailored specifically to the participants' individual skill level and goals.

Conflict of interest: The authors have declared no conflict of interest.

\section{References}

1. Huettig, C. \& Darden-Melton, B. (2004) Acquisition of Aquatic Skills by Children with Autism, Palaestra,20, 20-5.

2. Yilmaz, I., Yanardag, M., Birkan, B. \& Bumin, G. (2004). Effects of Swimming Training on Physical Fitness and Water Orientation in Autism. Pediatrics International 46: 624-6.

3. Guan, J., \& Li, G. (2017). Injury mortality in individuals with autism. American journal of public health, 107(5), 791-793.

4. Rimland, B. (1964). Infantile autism: The syndrome and its implications for a neural theory of behavior. New York: Appleton Century Croft.

5. Gleeson, E. (2016, September 23). ASD and Drowning. Retrieved December 20, 2017, Fromhttps://www. autismspectrum.org.au/sites/default/files/Factsheet_What $\% 20$ is\%20autism_ 20170306_1.pdf.

6. Pan, C. Y. (2010). Effects of water exercise swimming program on aquatic skills and social behaviors in children with autism spectrum disorders. Autism, 14(1), 9-28.

7. Porges, S. W. (2005). The role of social engagement in attachment and bonding. Attachment and Bonding, 33-54.

8. Yuan, P. Q., Taché, Y., Miampamba, M., \& Yang, H. (2001). Acute cold exposure induces vagally mediated Fos expression in gastric myenteric neurons in conscious rats. American Journal of Physiology-Gastrointestinal and Liver Physiology, 281(2), G560-G568.

9. Mason, H., Vandoni, M., Debarbieri, G., Codrons, E., Ugargol, V., \& Bernardi, L. (2013). Cardiovascular and respiratory effect of yogic slow breathing in the yoga beginner: what is the best approach? Evidence-Based Complementary and Alternative Medicine, 2013.

10. Wang, Y., Kondo, T., Suzukamo, Y., Oouchida, Y., \& Izumi, S. I. (2010). Vagal nerve regulation is essential for the increase in gastric motility in response to mild exercise. The Tohoku Journal of Experimental Medicine, 222(2), 155-163.

11. Becker, E.W. (2007). Micro-algae as a source of protein. 25(2), 207-210. https://doi.org/10.1016/j.biotechadv.2006.11.002

12. Kok, B. E., Coffey, K. A., Cohn, M. A., Catalino, L. I., Vacharkulksemsuk, T., Algoe, S. B.,\& Fredrickson, B. L. (2013). How positive emotions build physical health: Perceived positive social connections account for the upward spiral between positive emotions and vagal tone. Psychological Science, 24(7), 1123-1132. 
13. Scott, F. J., Baron-Cohen, S., Bolton, P., \& Brayne, C (2002). The CAST (Childhood Asperger Syndrome Test): Preliminary development of a UK screen for mainstream primary-school age children. Autism, 6, 9-31.

14. Gibson, J. J., \& Pick, A. D. (1963). Perception of another person's looking behavior. The American Journal of Psychology, 76(3), 386-394.

15. Dawson, G., \& Adams, A. (1984). Imitation and social responsiveness in autistic children. Journal of Abnormal Child Psychology, 12(2), 209-226.

16. Stone, W. L., Lemanek, K. L., Fishel, P. T., Fernandez, M. C., \& Altemeier, W. A. (1990). Play and imitation skills in the diagnosis of autism in young children. Pediatrics, 86(2), 267272.

17. Stahmer, A. C., \& Schreibman, L. (1992). Teaching children with autism appropriate play in unsupervised environments using a self-management treatment package. Journal of Applied Behavior Analysis, 25(2), 447-459.

18. Zak, P., \& Barraza, J. (2018, May 5) Immersion neuroscience platform. Retrieved from https://www.immersionneuro.com/ our-team/

19. Norris, C. J., Larsen, J. T., \& Cacioppo, J. T. (2007). Neuroticism is associated with larger and more prolonged electrodermal responses to emotionally evocative pictures. Psychophysiology, 44(5), 823-826.

20. Barraza, J. A., Alexander, V., Beavin, L. E., Terris, E. T., \& Zak, P. J. (2015). The heart of the story: Peripheral physiology during narrative exposure predicts charitable giving. Biological Psychology, 105, 138-143.

21. S, Baron-Cohen., S, Wheelwright., J, Hill., Y, Raste., I, Plumb.,(2001). The "Reading the Mind in the Eyes" Test revised version: a study with normal adults, and adults with Asperger syndrome or high-functioning autism. J Child Psychol Psychiatry, 42(2):241-51.
22. Kooij, D. T. A. M., Bal, P. M., \& Kanfer, R. (2014). Future time perspective and promotion focus as determinants of intraindividual change in work motivation. Psychology and Aging, 29(2), 319-328. https://doi.org/10.1037/a0036768

23. A, Kushki.,E, Drumm., Michele, P. M., Nadia, T.,Annie, D., Tom, C., Evdokia, A., (2013). Investigating the Autonomic Nervous System Response to Anxiety in Children with Autism Spectrum Disorders. https://doi.org/10.1371/journal.pone.0059730

24. Guo-li, M., Hongjun, S., (2005). Adult neurogenesis in the mammalian central nervous system. Annu Rev Neurosci, 28:223-50. doi: 10.1146/annurev.neuro.28.051804.101459.

25. Michelle, A. P., Angela, S., Bruce, H. F., Stephen, W. P., (2013). Respiratory sinus arrhythmia: A marker for positive social functioning and receptive language skills in children with autism spectrum disorders. https://doi.org/10.1002/dev.21002

26. Kok, B. E., \& Fredrickson, B. L. (2010). Upward spirals of the heart: Autonomic flexibility, as indexed by vagal tone, reciprocally and prospectively predicts positive emotions and social connectedness. Biological Psychology, 85(3), 432-436.

27. Fragala-Pinkham, M., Haley, S. M., \& O’Neil, M. E. (2008). Group aquatic aerobic exercise for children with disabilities. Developmental Medicine \& Child Neurology, 50(11), 822-827.

28. Getz, M., Hutzler, Y., \& Vermeer, A. (2006). Effects of aquatic interventions in children with neuromotor impairments: a systematic review of the literature. Clinical Rehabilitation, 20(11), 927-936.

29. Nichols, W. J. (2015). Blue mind. Little Brown. 


\section{Appendix A}

Social Skills Profile

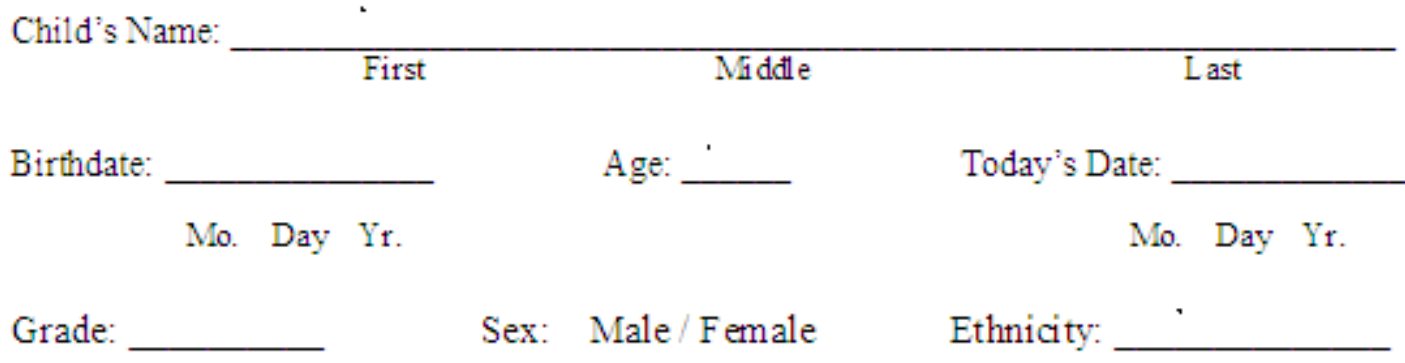

Parent/Guardian:

Relationship to Child: Mother Father Guardian Other

Please read the following questions car efully and circle the appropriate answer. All resp on ses are confidential.

1. Does she join in playing games with other children easily? Yes No

2. Does she come up to you spontaneously for a chat? Yes No

3. Was she speaking by 2 years old? Yes No

4. Does she enjoy sports? Yes No

5. Is it important to him/her to fit in with the peer group? Yes No

6. Does she appear to notice unusual de tails that
others miss?

7. Does she tend to take things literally? Yes No

8 . When she was 3 years old, did she spend a lot of time pretending (e.g., play-acting being a superhero, or holding teddy's tea parties)?

Yes No

9. Does s he like to do things over and over again,

in the same way all the time?

Yes No

10. Does s/he find it easy to interact with other children?

Yes No

11. Can s/he keep a two-way conversation going?

Yes No


12. Can s he read appropriately for his her age?

Yes

No

13. Does s he mostly have the same interests as his her peers?

Yes

No

14. Does s he have an interest which takes up so much time that $s$ he does little else?

Yes

No

15. Does s he have friends, rather than just acquaintances?

Yes

No

16. Does s he of ten bring you things $s$ he is interested in to show you?

Yes

No

17. Does s he enjoy joking around?

Yes

No

18. Does s he have difficulty understanding the rules for polite behaviour?

Yes

No

19. Does s he appear to have an unusual $m$ emory for details?

20. Is his her voice umusual (e.g., overly adult, flat, or very monotonous)?

$$
\text { Yes }
$$$$
\text { No }
$$

21. Are people important to him/her?

Yes

No

22. Can s he dress him/herself?

Yes

No

23. Is s he good at turn-taking in conversation?

Yos

No

24. Does s he play imaginatively with other children, and engage in role-play?

Yes

No

25. Does $s$ he of ten do or say things that are tactless or socially inappr opriate?

Yes

No

26. Can s he count to 50 without leaving out any numbers?

Yes

No

27. Does $s$ he make normal eye-contact?

Yes

No

28. Does s he have any unusual and repetitive movem ents?

Yes

No

29. Is his her social behaviour very one-sided and always on his her own terms?

Yes

No

30. Does s he sometimes say "you" or "she" when she means "I"?

Yes

No

31. Does s he prefer imaginative activities such as 
play-acting or story-telling, rather than numbers or lists of facts?

32. Does $s$ he sometimes lose the listener because of not explaining what $s$ he is talking about?

Yes

No

33. Can s he ride a bicycle (even if with stabilisers)?

Yes

No

34. Does s he try to im pose routines on him/herself, or on others, in such a way that it causes problem s?

Yes

No

35. Does $s$ he care how $s$ he is perceived by the rest of the group?

Yes

No

36. Does $s$ he of ten turn conversations to his her favourite subject rather than following what the other person wants to talk about?

Yes

No

37. Does s he have odd or unusual phrases?

Yes

No

\section{SPE CIAL NEE DS SE CTION}

Please com plete as ap prop riate

38. Have teachers health visitors ever expressed any concerns about his her developm ent?

Yes

No

If $\mathrm{Y}$ es, please specify

39. Has s he ever been diagnosed with any of the following?

L anguage delay

Yes

No

Hyperactivity/Attention Deficit Disorder (ADHD)

Yes No

Hearing or visual difficulties

Yes

No

Autism Spectrum Disorder, incl. Asperger's Syndrome

Yes

No

A physical disability

Yes

No

Other (please specify)

Yes

No

If $\mathrm{Y}$ es, please specify

Background Questionnaire and Social Skills Profile 


\section{Effects of Aquatic Therapy on Vagal Tone and Social Behaviors in Individuals with Autism Spectrum Disorder}

\section{Appendix B}

\section{Sw im Experience Survey}

Participant Name:

For questions 1-2 please circle the number that represents your level of agreement to the statement.

1. My child is attracted to water.

$\begin{array}{ccccc}\text { Strongly Agree } & \text { Somewhat Agree } & \text { Neural } & \text { Somewhat disagree } & \text { Strongly disagree } \\ 1 & 2 & 3 & 4 & 5\end{array}$

2. My child enjoys being in water.

$\begin{array}{ccccc}\text { Strongly Agree } & \text { Somewhat Agree } & \text { Neural } & \text { Somewhat disagree } & \text { Strongly disagree }\end{array}$

For Question 3-5 please select the resp onse that b est rep resents your experience.

3. Has your child had a near drowning or negative experience in water?
a. Yes
b. No
If yes, please describe the experience below.

4. Has your child had swim lessons?
a. Yes
b. No

If yes, how many swimlessons has your child had?
c. $1-4$
d. $5-8$
e. $9+$

5. What level swimmer is your child?

a. Water Discovery: Child can respond to verbal cues and jump on land

b. Water Exploration: Child is comfortable working with an instructor without a parent in the water

c. Water Accumulation: Child will go under water voluntarily

d. Water Movement: Child can do a front or back float on their own

e. Water Stamina: Child can swim 10-15 yards on their front or back

f. Stroke Introduction: Child can swim 15 yards, front or back crawl

g. Stroke Development: Child can swim across the pool front crawl, back crawi and breaststroke

h. Stroke Mechanics: Child can swim across the pool and back front crawl, back crawl and breaststroke 


\title{
Effects of Aquatic Therapy on Vagal Tone and Social Behaviors in Individuals with Autism Spectrum Disorder
}

\begin{abstract}
Appendix C

\section{Development of the Intervention}

The author of this study is an avid swimmer and a clinician experienced in working with children with ASD. In this role, the author discovered a need for aquatic programs tailored for children with ASD as they were not frequently available in the community. Drawing on her two expertise, the author developed an aquatic program for children with ASD. While the intention was only to teach swimming skills, the author noticed improvements is speech and social skills during the aquatic sessions. Surprisingly, nonverbal clients began speaking during the sessions. Multiple families were thrilled with the results of the program, both intended and non-intended. Many of those families continued the program years after their child learned to swim because they were pleased with the social skills improvements seen in the water and following the program. From there, the author began to design a study to test this hypothesis formally.
\end{abstract}

